\title{
MODALIDAD NARRATIVA EN AURA: REALIDAD Y ENAJENACION
}

\author{
POR \\ SANTIAGO ROJAS \\ Eastern New Mexico University
}

Desde la publicación de Aura la crítica se ha ocupado con frecuencia de esta novela corta de Carlos Fuentes y en muchas oportunidades se han emitido juicios que realmente sorprenden por su disparidad. Para Luis Harss y Bárbara Dohmann, Aura no pasa de ser una elusiva novelita de misterio, que adolece de flagrantes deslices de estructura y estilo y por todo ello no alcanza a convencer positivamente al lector ${ }^{1}$. René Jara opina que «es una noveleta bien hecha de saber decadente», agregando a renglón seguido este comentario con relación al novelista: «La fuerza de su obra anterior parece haberlo agotado prematuramente» ${ }^{2}$. Manuel Durán, en cambio, cataloga a Aura como «obra perfecta», y Emir Rodríguez Monegal, sin dejar de hacer hincapié en las dificultades que el relato depara al crítico y al lector, la considera como una de las obras más logradas del conocido escritor mexicano ${ }^{3}$. El propio Fuentes, además, según Daniel de Guzmán, tiene a Aura en alta estima y también la reconoce como una de sus mejores creaciones ${ }^{4}$.

Enmanuel Carballo, en una entrevista sostenida con el escritor, haciendo un paréntesis a los comentarios autocríticos de Fuentes, anota esta elogiosa valoración:

Se ha dicho, y con razón, que Aura (1962) es una obra maestra de la narrativa mexicana. Obra maestra porque en ella no se distin-

\footnotetext{
Into the Mainstream: Conversations with Latin American Writers (New York: Harper and Row, Publishers, 1966), pp. 301-302.

${ }^{2}$ «El mito y la nueva novela hispanoamericana. A propósito de La muerte de Artemio Cruz», según Helmy F. Giacoman, Homenaje a Carlos Fuentes: Variaciones interpretativas en torno a su obra (New York: Las Américas, 1971), p. 170.

${ }^{3}$ Tríptico mexicano (México: Sep Setentas, 1971), p. 78; Narradores de esta América, tomo 2 (Buenos Aires: Editorial Alfa Argentina, 1974), pp. 253-254, 263.

${ }^{4}$ Carlos Fuentes (New York: Twayne Publishers, Inc., 1972), p. 124.
} 
guen, como unidades autónomas, la forma y el fondo, la intención y la realización, el sueño y la realidad. En ella todo es uno y lo mismo: es una obra de atmósfera más que de personajes o de acción. Atmósfera construida con palabras, palabras que, extraño caso, solicitan y obtienen la comparecencia de la poesía. Y es ésta, la poesía, la que permite el desdoblamiento de los personajes, la fusión del pasado y el presente, la identificación del amor y del horror ${ }^{5}$.

Poco más adelante, aludiendo a cuestiones de estilo, Carballo concluye su observación con estas palabras: «El empleo de la segunda persona del singular para describir los sucesos es un obstáculo que el autor salva limpiamente ${ }^{6}$. No obstante la cita anterior, muchas de las dificultades que ofrece el complejo mundo elaborado en Aura radican precisamente en el uso de la segunda persona singular como voz narrativa, que se expresa alternando el tiempo presente con el futuro. La dificultad estriba en que la segunda persona singular es pasiva, receptora, y se supone, por tanto, la existencia de un "yo» activo que genera y comunica la acción. Reconocer en Aura esas dos voces, el "tú " que abre y cierra el relato y, más que nada, el admisible "yo" que se oculta en el fondo, no es, en modo alguno, empresa libre de escollos en el análisis del contenido y de la realización de la obra. Identificar el «tú» es en apariencia fácil, porque desde el primer párrafo esa segunda persona singular alude directamente a Felipe Montero. Al concluir la novela, sin embargo, como ha sido observado por la crítica, se manifiesta la ambigüedad, dado que el lector descubre con sorpresa que dicho personaje pierde su original forma de ser y se transmuta en la personalidad del desaparecido general Llorente ${ }^{7}$.

Esclarecer, en cambio, la identidad del hipotético «yo» es tarea mucho más escabrosa, aunque la opinión más compartida hasta el momento es que dicha voz se identifica con Felipe Montero, personaje a quien se ha visto siempre como el protagonista de la novela. Manuel Durán, por ejemplo, al comentar el efecto que tiene en Aura el empleo del procedimiento estilístico del «tú», afirma enfáticamente «que sabemos, o deberíamos saber, desde el principio que el autor se está refiriendo al narrador y que 'tú' significa 'yo'» ${ }^{8}$. Del mismo modo, Richard M. Reeve, en su estudio «Carlos Fuentes y el desarrollo del narrador en segunda per-

${ }^{5}$ Diecinueve protagonistas de la literatura mexicana del siglo $X X$ (México: Empresas Editoriales, S. A., 1965), p. 430.

Ibid., p. 431.

${ }^{7}$ Lanin A. Gyurko, «Identity and the Demonic in Two Narratives by Fuentes», Revista de Letras, tomo VI, núm. 21 (1974), pp. 96-97.

${ }^{8}$ Tríptico, p. 83. 
sona: Un ensayo exploratorio», explicando las características y las variaciones observadas en creaciones precedentes que se valen de dicho recurso, indica: «El verdadero narrador en segunda persona emplea el 'tú' al hablar de sí mismo», y cita como ejemplo el primer párrafo de Aura ${ }^{9}$.

Robert G. Mead, Jr., por su parte, también arriba a la misma conclusión y admira en Fuentes la maestría «de 'contar' la historia por boca del otro Felipe Montero, alter ego del protagonista...» ${ }^{10}$. Partiendo de esta afirmación, Mead concluye que toda la novela, «de comienzo a fin, es un sueño largo e ininterrumpido, una cadena de sucesos, experiencias, sensaciones, que nacen, viven y mueren en la imaginación de Felipe Montero» ${ }^{11}$.

Esta aproximación crítica relativa al personaje y al relato en general suscita, empero, no pocas interrogaciones. En primer lugar, si la novela ha de ser interpretada en función de la novela misma, la frustración profesional del joven historiador «cargado de datos inútiles» y la debilidad de su carácter no alcanzan a explicar en forma convincente la causa que genera la elaboración de ese macabro mundo de locura ${ }^{12}$. Todo lo que el lector 1lega a conocer de Felipe no justifica ni armoniza con la desmesurada dimensión que alcanza ese engendro de pesadilla, fruto sin duda de una conciencia torturada y enfermiza; ni aclara el origen que motiva la aberración erótica ni el conocimiento y práctica del conjuro hechicero, satánico, que son los pilares y el fundamento que forman y sostienen la compleja estructura del relato.

Por otra parte, si la narración no es un producto imaginario fraguado en la conciencia o subconsciente de Felipe y éste llega en realidad a la casa de la viuda del general Llorente, donde experimenta todas las vivencias que supuestamente narra, entonces el personaje resulta demasiado cándido para ser verosímil. Difícil sería, además, explicar la corporalidad de Aura - Felipe la ve, escucha y palpa - como la encarnación de la juventud de doña Consuelo, mucho más cuando ambas mujeres aparecen juntas en repetidas ocasiones.

Por las razones apuntadas, descontando al joven profesor de historia como fuente del posible "yo», no queda más alternativa que analizar al respecto las posibilidades que brinda doña Consuelo. Dicha opción, aunque sorprende a primera vista, abarca y explica muchas de las interro-

${ }^{9}$ Helmy F. Giacoman, Homenaje, p. 79.

10 «Carlos Fuentes, airado novelista mexicano», Hispania, L, 2 (1967), p. 233.

${ }^{11}$ Ibíd., p. 233.

${ }^{12}$ Carlos Fuentes, Aura (México: Alacena, 1962), p. 9. Las próximas citas del texto provendrán de esta edición y sólo se indicará entre paréntesis el número de las páginas. 
gaciones que desde el principio asedian al lector, ofreciendo a la vez respuestas que se apoyan en antecedentes de la propia novela. Adoptando este punto de vista, las memorias del general Llorente cobran de inmediato una importancia fundamental y reveladora. A través de ellas, Fuentes, en rápida visión del pasado, descubre al lector períodos claves de la juventud de doña Consuelo y perfila a grandes trazos su singular personalidad. Preciso es poner de relieve, por el momento, tres características que la peculiarizan. En primer lugar, se trata de una mujer que sufre de un agudo complejo de narcisismo y vive, en consecuencia, profundamente enamorada de su extraordinaria belleza física y de su juventud, razones que crean en ella un mórbido temor a la vejez. Tal es el orgullo nacido de su hermosura, que, según afirma el general Llorente en las memorias, la adolescente esposa estaría dispuesta a todo, a fin de conservar para siempre los atributos de su exuberante juventud. Luego, como segunda característica, adolece de un desmedido apetito erótico, nacido probablemente de un imperioso pero frustrado anhelo de maternidad. Aunque irradia vida y ama a su marido, su entraña jamás logra concebir al hijo que tanto anhela. Finalmente, rebelde ante la ironía de la vida, la joven esposa enloquece, entregada con tesón a buscar en la hechicería el elixir prodigioso que le asegure juventud y fertilidad. «Le advertí a Consuelo —atestigua el general- que esos brebajes no sirven para nada: ella insiste en cultivar sus propias plantas en el jardín. Dice que no se engaña. Las hierbas no la fertilizarán en el cuerpo, pero sí en el alma...» (p. 55).

En efecto, desde muy temprana edad, todavía en Francia y vivo aún el general Llorente, doña Consuelo, desorientada ya en las sombras de la locura y adormecida por el efecto de potentes narcóticos, reclama el triunfo de la fertilidad de su alma y el encuentro con su propia juventud. De esta manera lo registra el condolido esposo: "La encontré delirante, abrazada a la almohada. Gritaba: 'Sí, sí, sí, he podido: la he encarnado; puedo convocarla; puedo darle vida con mi vida» (p. 55). En otro momento la sorprende en pleno período de trance díciendo en voz alta: "Voy hacia mi juventud, mi juventud viene hacia mí (p. 55).

La trascendencia de ese pasado y el consecuente efecto psicológico ejercido en la vida y conducta de doña Consuelo no deben pasar en forma inadvertida, porque se convierten en instrumento de capital importancia para la comprensión e interpretación de los sucesos que la novela establece como presente. La viuda, ahora inmensamente vieja, pues ha cumplido ciento nueve años - sesenta de viudez-, está de regreso en México, no se sabe desde cuándo. En la soledad de la vieja casona, aunque asida al pasado, vive al mismo tiempo entregada a las ilusiones que 
nacen de su enajenación. Cultiva, como antaño, plantas exóticas y alucinógenas; rinde culto a imágenes religiosas, divinas y satánicas; confía en extraños amuletos y, completamente convencida de poseer la capacidad de reencarnar la ya perdida juventud, con una devoción sólo dable en la prodigiosa fertilidad de su alma, se lanza ahora a forjar su más atrevido sueño: efectuar el renacimiento del amado en cuerpo y alma para así disfrutar del deleite amoroso más allá del tiempo y de la muerte. Aura es, en efecto, más que nada, una admirable historia de amor, sublime y macabra, que se desarrolla y centra en la interioridad de un solo personaje: la enloquecida doña Consuelo, viuda de Llorente.

El propio escritor ha confesado que la novela se inspira en un personaje histórico femenino que le ha subyugado desde temprana edad: «Mi obsesión nació en mí cuando tenía siete años, y después de visitar el castillo de Chapultepec y ver el cuadro de la joven Carlota de Bélgica, encontré en el archivo Casasola la fotografía de esa misma mujer, ahora vieja, muerta, recostada dentro de un féretro acojinado, tocada con una cofia de niña: la Carlota que murió, loca, en un castillo, el mismo año que yo nací. Las dos Carlotas: Aura y Consuelo. Quizá Carlota nunca supo que envejecía. Hasta el fin escribía cartas de amor a Maximiliano. Correspondencia entre fantasmas» ${ }^{13}$. Ello explica, asimismo, el título y el epígrafe de la novela, esa sentencia de Jules Michelet inspirada en la mujer: «El hombre caza y lucha. La mujer intriga y sueña; es la madre de la fantasía, de los dioses. Posee la segunda visión, las alas que le permiten volar hacia el infinito del deseo y de la imaginación... Los dioses son como los hombres: nacen y mueren sobre el pecho de una mujer...» (p. 7).

Felipe Montero, por tanto, a pesar de su indiscutible importancia, no es realmente el protagonista, porque sólo constituye una concepción fantástica engendrada por doña Consuelo y, por consiguiente, al carecer de independencia, únicamente sirve de instrumento para que la anciana enamorada procure alcanzar por medio de él la realización de un sueño que satisfaga sus fallidas aspiraciones.

Este es precisamente uno de los recursos más admirables de Aura. E1 escritor descubre así, en dos planos diferentes, el extraño y complejo funcionamiento psicológico de la anciana, loca y bruja. Por una parte, ella crea en su imaginación a Felipe, pero acto seguido se distancia de él, otorgándole una aparente independencia y dotándole de características que, aunque propicias al fin por ella anhelado, poseen a la vez un

${ }^{13}$ Carta de Carlos Fuentes a Gloria Bradley Durán, fechada el 8 de diciembre de 1968. Citada por Manuel Durán, Tríptico, p. 95. 
admirable y vívido tono realista. La autonomía de Felipe, aunque ilusoria, es absolutamente necesaria en el plan urdido por la anciana. Después de todo, la concreación de su sueño debe contar con un convincente grado de verosimilitud que logre satisfacer los escrúpulos de su propia conciencia entenebrecida. Este es el plano que proyecta la visión realista de la novela, magistralmente logrado. En él, doña Consuelo, en secreta autodeterminación, se relaciona con el joven profesor de historia que se encargará de revisar y concluir las memorias de su marido, tratándolo respetuosamente como «el señor Montero».

Una vez concebido el personaje, surge entonces un segundo nivel de creación. En esta etapa prevalece la hechicera, la bruja, quien, siempre oculta y en posesión de misteriosos poderes, se entrega con abínco a hipnotizar al fruto creado en su propio espíritu, hasta hacerle creer a él - y también a sí misma- que reencarna la juventud del desaparecido general Llorente. La anciana personifica de este modo el encubierto "yo" que se dirige a la conciencia $\circ$ al subconsciente del joven traductor, creando con ello el inusitado punto de vista con que se narra la novela.

De allí proviene ese «tú» que tiene «una especie de efecto hipnótico» en Felipe, y explica la conducta dócil, casi mecánica, del personaje ${ }^{14}$. Nótese el determinismo que lo anima e impulsa a traspasar los umbrales de la vieja mansión de Donceles, 815: «La puerta cede al empuje, levísimo, de tus dedos, y antes de entrar miras por última vez sobre tu hombre... Tratas inútilmente de retener una sola imagen de ese mundo exterior indiferenciado» (pp. 11-12), tan opuesto, por cierto, a la fantasmal atmósfera interior de la solitaria casona a la cual entra con tan sorprendente mansedumbre. Lanin A. Gyurko, comentando el uso de la segunda persona singular en Aura, hace esta oportuna observación: «A hypnotist often employs the second person as he addresses the individual who is being placed under a trance, in order to suggest to him, or to his subconsciousness, the behavior that he should carry out» ${ }^{15}$.

Aunque el relato se estructura según el orden de los acontecimientos con relación a Felipe, ha de tenerse siempre en cuenta que éste no es la voluntad generatriz y que los episodios no se presentan como él los dispone o narra, sino como se los dicta ese hipotético "yo" dominante y oculto. En ciertas ocasiones, dejando de lado lo que ocurre en el presente, el "yo» se anticipa a los hechos y le anuncia abiertamente el porvenir. Es cuando en la novela se hace uso del futuro, tiempo que ayuda a establecer una insinuante atmósfera de misterio y evidencia al mismo

\footnotetext{
${ }^{14}$ Ibid., p. 83.

15 «Identity», p. 98.
} 
tiempo el papel secundario y dependiente que le corresponde a Felipe. No existen alternativas para él; está fatalmente destinado a cumplir, paso a paso, las etapas prefijadas para llevar a feliz término la realización de un anhelo ajeno a su voluntad.

Las fases y los procedimientos empleados por la anciana para alcanzar la consumación de su sueño, aunque múltiples y complejos, no son por ello imposibles de señalar. El complicado mecanismo tiene su punto de partida en el anuncio aparecido en el periódico, tan hábilmente elaborado que el propio Felipe reconoce que en él sólo falta su nombre. La intención y los intereses que guían a doña Consuelo, sin embargo, se dejan ver desde el primer renglón del aviso: «Se necesita historiador joven» (p. 9). Importa señalar de inmediato que queda así explícitamente estipulado el sexo del candidato y se asigna a la vez una curiosa importancia a la edad del mismo. El texto del anuncio reitera poco más adelante: "Juventud, conocimiento del francés, preferible si ha vivido en Francia» (p. 9). En otras palabras: una mujer o un hombre de avanzada edad, por muy competentes que fuesen en el conocimiento de la historia y de la lengua francesa, no alcanzarian a cumplir con lo esencial de los requisitos. Todo queda, pues, automáticamente supeditado a la edad y sexo del postulante, condiciones de importancia vital en el plan fraguado por la demente.

La creación de Felipe y su ulterior comportamiento parecen responder, además, a patrones previamente experimentados por la anciana. La forma en que el joven llega a la mansión de la viuda, como lo ha hecho ver José Otero, posee una significativa semejanza con el modo en que se produce el encuentro de doña Consuelo y la sugestiva encarnación de sus años juveniles ${ }^{16}$. El general Llorente describe así la trascendente escena: «Pasó sin mirarme, pero sus palabras iban dirigidas a mí. 'No me detengas - dijo-; voy hacia mi juventud, mi juventud viene hacia mí. Entra ya, está en el jardín, ya llega'...» (p. 55) ${ }^{17}$. Del mismo modo cabe poner de relieve la conducta hipnótica y sonambulesca de Felipe, la cual halla su paralelo en el mecánico proceder de Aura, precisamente como si ésta sirviese de modelo al comportamiento mostrado por aquél. El poder de atracción que la doncella ejerce sobre el iluso profesor de historia manifiesta asimismo íntima concordancia con la manera en que Consuelo, en los días de su esplendente juventud, seduce al apuesto general de las fuerzas de Maximiliano. Ambas mujeres, una creada a imagen de la otra, hermosas y siempre vestidas de verde, guardan el secreto

\footnotetext{
${ }^{16}$ «La estética del doble en Aura, de Carlos Fuentes», Explicación de Textos Literarios, V, núm. 2 (1976), p. 186.

${ }^{17} \mathrm{El}$ énfasis es mío.
} 
primordiál de su atracción en el fascinante color de sus pupilas: «... ce sont ses yeux verts qui ont fait ma perdition...» (p. 38), confiesa cándidamente el general. Felipe, por su parte, también ha de sentir el embrujo que irradia la tierna mirada de la inasible Aura: «Al fin podrás ver esos ojos de mar que fluyen, se hacen espuma, vuelven a la calma verde, vuelven a inflamarse como una ola: tú los ves y te repites que no es cierto... Sin embargo, no te engañas: esos ojos fluyen, se transforman, como si te ofrecieran un paisaje que sólo tú puedes adivinar y desear» (p. 18).

La belleza de Aura, no obstante, es sólo uno de los recursos de que se vale la anciana para cautivar a Felipe. Todo el ambiente de la casa, saturado de misterio y magia, influye sobre él. Sus sentidos perciben con frecuencia sensaciones que aparecen y desaparecen, o de cuya realidad no está seguro, creando en su espíritu una propicia actitud de incertidumbre, que socava paulatinamente la voluntad y lo prepara para aceptar la transmutación final manipulada por la bruja.

Dicho traspaso de identidad, piedra angular en el desarrollo de la trama y en el prolijo andamiaje construido por la anciana, parece quedar simbolizado en el intercambio de llaves que realizan los personajes ${ }^{18}$. Felipe, que al principio se muestra inclinado a rehuir la residencia en la casa, ve desvanecerse una esperanza de escape cuando Aura le informa que un criado ya ha traído sus pertenencias a la mansión de la viuda. Luego, sin ceder del todo al empeño de salir de la casa y al descubrir por azar un llavín que porta en los bolsillos, declara a la joven: «iAh! Olvidé que un cajón de mi mesa está cerrado con llave. Allí tengo mis documentos» (p. 23). Ella, al parecer sospechosa de la verdadera intención de Felipe, contesta con aire de reproche, y él, confuso y rendido, poco más tarde deposita el llavín como prenda en la palma de la mano, delicada y tersa, de la muchacha. Aura aprisiona el objeto con efusión, busca con su mirada los ojos de Felipe, musita "gracias» y se separa de él, saliendo con prisa de la habitación. El hecho de que se trate de la llave que guarda los documentos del recién 1legado, referencia quizá a los papeles de identidad del mismo, cobra de pronto inusitado valor. Dicha importancia aumenta cuando el lector descubre que Aura, en la intimidad de la primera entrega amorosa, desnuda sobre el cuerpo de Felipe, agita levemente el llavín y finaliza los goces de la cita con este murmullo: «Eres mi esposo» (p. 36). El enigmático «yo», siempre oculto, afirma de inmediato: «Tú asientes...» (p. 36).

is Lanin A. Gyurko («Identity», p. 112) también destaca este intercambio de llaves como símbolo del traspaso de identidad experimentado por Felipe. 
Doña Consuelo, por su parte, en curioso intercambio, también entrega a Felipe la llave del baúl donde guarda celosamente su vestido de boda, las memorias y otros documentos del general. Después de poner el primer folio en manos del joven traductor, la viuda declara: «No, no; quédese con la llave. Acéptela. Confío en usted» (p. 27). En el último capítulo de la novela, ésta es precisamente la llave que Felipe, nervioso, aprisiona en el puño y con la cual abre el arcón, de donde sustrae las páginas finales de las memorias y las fotografías que le revelan y le inducen a creer en su nueva identidad: "Verás, en la tercera foto, a Aura en compañía del viejo, ahora vestido de paisano, sentados en una banca, en un jardín. La foto se ha borrado un poco: pero es ella, es él, es... eres tú» (p. 56). En el párrafo siguiente, Felipe, perplejo frente a la macabra revelación que le descubren los viejos retratos, afina la observación: «Pegas esas fotografías a tus ojos, las levantas hacia el tragaluz: tapas con una mano la barba blanca del general Llorente, lo imaginas con el pelo negro y siempre te encuentras borrado, perdido, olvidado, pero tú, tú, tú» (p. 56).

Felipe, de este modo, se percata por fin de la horrenda realidad ya anunciada a su espíritu en forma premonitoria en el segundo encuentro amoroso. El acto sexual, en sacrílega mezcla de lo sagrado y lo erótico, se realiza entonces bajo el signo ritual de la Eucaristía y procura repetir en su esencia el sublime misterio de la transustanciación ${ }^{19}$. En la conciencia de la loca, éste es el instante que opera el milagro, reafirmando en su espíritu las sublimes promesas del amor, sintetizadas en el siguiente diálogo de la pareja, aún desnuda y fundida en apretado abrazo:

$-i$ Me querrás siempre?

-Siempre, Aura; te amaré para siempre.

- ¿Siempre? ¿Me lo juras?

-Te lo juro.

-iAunque envejezca? ¿Aunque pierda mi belleza? ¿Aunque tenga el pelo blanco?

-Siempre, mi amor; siempre.

- ¿Aunque muera, Felipe? ¿Me amarás siempre, aunque muera?

- Siempre, siempre. Te lo juro. Nada puede separarme de ti.

-Ven, Felipe, ven... (pp. 47-48).

${ }^{19}$ La relación y semejanza del acto sexual con los símbolos establecidos durante la Pasión de Cristo es obvia. Probablemente todo el proceso concebido por la demente procura imitar al divino misterio. La novela se desarrolla en tres días y en el último se produce la «muerte» de Felipe y la «resurrección» del amado. Aura, además, haciendo eco del concepto cristiano dice al joven profesor: «Hay que morir antes de renacer...» (p. 51). 
Concluido el encuentro y el juramento amoroso, Aura se reúne con la anciana, sentada en una silla en el fondo del cuarto, y Felipe descubre con asombro «que la vieja ha estado todo el tiempo en la recámara» (p. 48). Las dos mujeres, con movimientos idénticos y simultáneos, le sonríen, agradecen y pasan lentamente al cuarto de la anciana. Cansado, insatisfecho, el joven profesor duerme, pero al despertar a la mañana siguiente busca con inquietud «la doble presencia de algo que fue engendrado la noche pasada» (p. 49). El invisible «yo», haciendo mayor la confusión de espíritu en Felipe, agrega en seguida esta tremenda afirmación: «Te llevas las manos a las sienes tratando de calmar tus sentidos en desarreglo: esa tristeza vencida te insinúa, en voz baja, en el recuerdo inasible de la premonición, que buscas tu otra mitad, que la concepción estéril de la noche pasada engendró tu propio doble» (p. 49) ${ }^{20}$.

En la tercera y última cita amorosa, cumplidas con éxito todas las etapas del macabro proceso, Felipe, atónito y vencido, se descubre a sí mismo abrazado al cuerpo desnudo de la anciana, que se estremece ligeramente "porque tú lo tocas, tú lo amas, tú has regresado también...» (p. 60), dice el escondido "yo», en obvia referencia al doble retorno del amado: el regreso a la juventud y a los brazos de la fiel compañera. E1 lector comprende al instante por qué la anciana, en preparación para el encuentro, se ha vestido aquel día con el amarillo traje de novia extraído del arcón. Con la cabeza hundida en el pecho de la alucinada, Felipe escucha, sin hacer resistencia, la última promesa de la loca: «Volverá, Felipe; la traeremos juntos. Deja que recupere fuerzas y la haré regresar...» (p. 60).

Este pasaje clave de la novela es la única referencia en que el misterioso "yo», lejos de aludir al alter ego de Felipe, se identifica plenamente con doña Consuelo y sin que ésta se valga de la recreación de su propio doble como intermediario. Segura de haber llegado al instante preciso del desenlace, se desenmascara por fin y enrostra al joven profesor el "tú » familiar que hasta entonces sólo había dirigido a la conciencia del personaje. Con la misma certidumbre que en el pasado concibe en su espíritu la creación de Aura, para perpetuar la ilusión de su belleza y juventud, se abraza ahora a Felipe, reencarnación del amado, para eternizar de este modo el sueño del amor y la pasión.

${ }^{20}$ La última parte de la cita parece encerrar una contradicción, pero aunque alude a Felipe, ese aparente contrasentido ilustra con exactitud la tragedia experimentada por doña Consuelo. Como pareja, la concepción nunca se logra, por razones de esterilidad, y como la esposa jamás consigue la descendencia carnal que tanto ansía, la locura le lleva a creer que puede al menos engendrar en su espíritu. 
Aura, por tanto, a la luz del presente estudio, no es la historia del joven traductor que llega a la casa de doña Consuelo atraído por un lucrativo empleo, sino más bien la conmovedora narración de una enajenada, viuda y decrépita, que crea en su imaginación a Felipe como medio para obtener el triunfo de sus sueños. La anciana, «enterrada en una casona que se ha ido convirtiendo en mausoleo por el fatal encajonamiento a que la someten las nuevas construcciones del México actual», evade así la estéril soledad de su existencia y logra, merced a un esfuerzo que trasciende la realidad y el tiempo, vivir con los fantasmas engendrados en la inagotable fertilidad de su alma ${ }^{21}$.

${ }^{21}$ Emir Rodríguez Monegal, Narradores, p. 258. 
